DAMANSKI, M. (I965). F. Urol. 93, 466.

Doggart, J. R., Guttmann, L. \& Silver, J. R. (I966). Paraplegia, 3, 229.

GibBon, N. (1958). Brit. F. Urol. 30, I.

GibBon, N. (1963). Lancet, 2, I3I3.

Gibbon, N. (1966). Acta Neurol. Scandinav. 42, 133.

Guttmann, L. (I949). Brit. Surg. Pract. 6, 445.

Guttmann, L. \& Frankel, H. (I966). Paraplegia, 4, 63.

Kyle, E. W. (1968). Paraplegia, 6, I.

Lapides, J., Ajemian, E. P. \& Lichtwardt, J. R. (i960). F. Urol. 84, 809.

Nyquist, R. H. \& Bors, E. (1967). Paraplegia, 5, 22.

O’Grady, F. \& CatTell, W. R. (I966). Brit. F. Urol. 38, I49, I 56.

Percival, A., Brumfitt, W. \& DE Louvois, J. (1964). Lancet, ii, IO27.

PRICE, M. (I968). Paraplegia, 6, 22.

Ross, J. C., Damanski M. \& Gibbon, N. (1960). Brit. F. Surg. 47, 636.

TALBOT, H. S. (1958). F.A.M.A. 168, I 595.

Tribe, C. R. (1963). Paraplegia, I, I9.

Vellacott, P. N. \& WebB-Johnson, A. E. (I9I9). Lancet, I, 733.

Wells, C. A. (1952). Prostatectomy. Edinburgh and London: E. \& S. Livingstone.

Wilmot, C. B. \& O'FlynN, J. D. (1967). Urol. Dig. 6, I7.

\title{
THE UPPER URINARY TRACT IN NEUROGENIC DISTURBANCES OF MICTURITION WITH SPECIAL REFERENCES TO NON-TRAUMATIC AETIOLOGY
}

\author{
By M. L. Allert, M.D., M. Bressel, M.D., and J. Sokeland, M.D. \\ University Hospital of Neurology, Homburg/Saar and University Hospital \\ of Urology, Homburg/Saar (Germany)
}

THE neurogenic disturbances of micturition of traumatic or non-traumatic aetiology are different in substantial aspects. Whereas the onset of traumatic lesions is immediate it is nearly impossible to determine the beginning and course of those with non-traumatic aetiology. As a result an exact classification of the type of bladder disturbance is rarely possible in the latter-in contrast to the traumatically conditioned disturbances which are usually classified according to Bors (1967). This leads to considerable problems as regards therapy and prognosis.

What is known about the upper urinary tract in such cases? Literature does not show details regarding this question-neither the classical works by Meyer (1928) and Adler (I 920) nor by one of the latest authors; they primarily deal with the problem of reflux, as may be seen from the recent extensive studies by Guttmann and Frankel (1966), Walsh (I968), and Talbot et al. (1968).

We have chosen 50 patients at random with neurogenic disturbances of micturition in order to find an answer to our question. The findings were collected and analysed by means of an electronic computer-system. The corresponding method was outlined in detail at the Urologists Congress, Lüttich, in 1967 (Albert, Bressel and Sökeland). Six patients were excluded because their examination results did not allow a comparison.

Table I shows sex and age of our patients. The relation between the number of men to that of women is approximately $3: \mathrm{I}$. The youngest patient was $\mathrm{I} 6$ and the oldest 76 years old. Most were between 20 and 59 years old, the majority between 50 and 59 . 
Table II shows our subjects classified according to clinical diagnosis. The number of disseminated sclerosis is the largest. But we should like to draw attention also to the cases of parkinsonism and pharmacogenic troubles.

TABLE I

Age and Sex

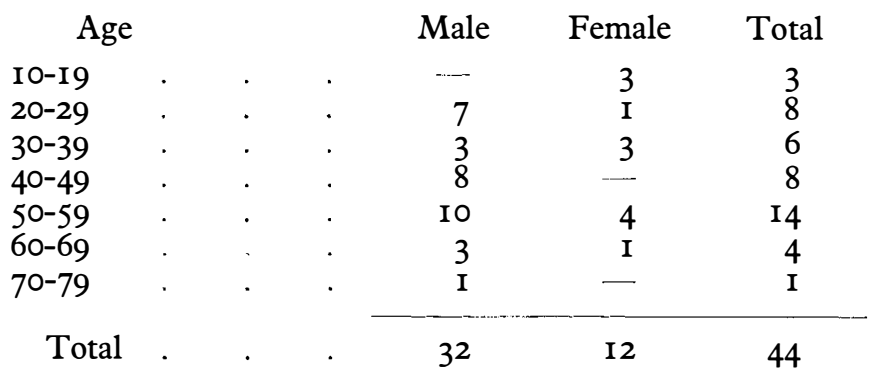

TABLE II

Frequency of Basic Diseases

Disseminated

Diagnosis

Male Female Total

$\cdot+\quad \cdot \quad+\quad$ I I

Extramedullary compression . . . . . . $\quad 4$

Encephalomalacia

Postvaccinal encephalitis

Polyneuritis

Paralysis agitans

Tabes dorsalis

Spinal process of obscure aetiology

Myelic and spinal malformations

Acute transverse myelitis

Disk hernias

Pharmacogenic disturbances

Peripheral pressure damage

Total

I 4 I5

$4 \quad-\quad 4$

$\begin{array}{lll}-- & \text { I } & \text { I } \\ -- & \text { I } & \text { I }\end{array}$

$\begin{array}{rrr}\text { I } & \cdots & \text { I } \\ 2 & \text { I } & 3\end{array}$

$2 \quad 2$

$\begin{array}{lll}5 & \text { I } & 6\end{array}$

$\begin{array}{ccc}2 & \text { I } & 3 \\ -- & \text { I } & \text { I }\end{array}$

\begin{tabular}{rrr}
2 & & 2 \\
3 & I & 4 \\
-- & I & I \\
\hline 32 & I2
\end{tabular}

The next three tables contain the clinical symptoms of the diseases just mentioned which allow to draw certain conclusions regarding the kind of disturbances of micturition.

One patient suffered from isolated micturition anomalies due to encephalitis caused years ago by vaccination. In four other cases we did not obtain information about the aetiology of the bladder disturbance from the clinical findings but exclusively from a thorough study of case-histories. These cases were of pharmacogenic origin, results which recently were published by Litvak et al.

The duration of the diseases is given in Table VI. Only a few had been in existence for some weeks, most of them one to six months, and some had been manifest for more than two years.

The patients mainly complained about retention of urine or delayed micturition (see Table VII). 
TABLE III-Motor Symptoms

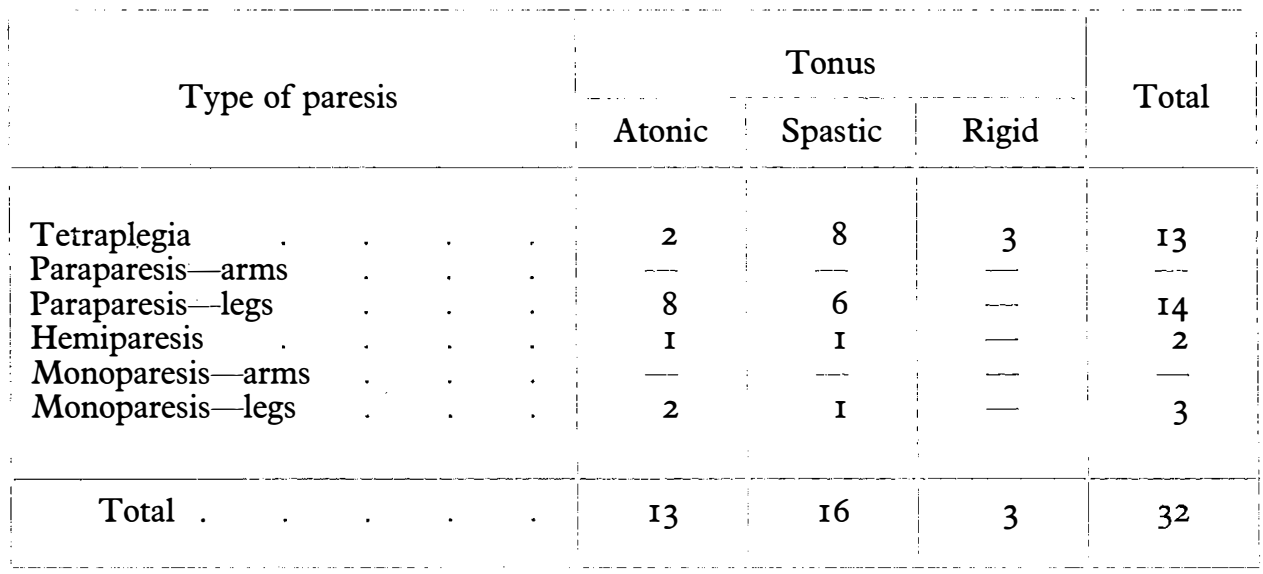

TABLE IV-Sensory Symptoms

Sensory failure zone

Number of patients

Transverse above $\mathrm{D}_{12}$

2

Transverse above $\mathrm{L}_{5}$

2

Transverse above $S_{5}$

Localisation: extremities

In form of a quadrant

Total

I

I

I

7

TABLE V-Various Symptoms

Ingestion of psychopharmacon .

Postencephalitic state

Disseminated sclerosis with isolated cranial nerve disturbances

Total

$\overline{6}$

TABLE VI-Duration of the Neurological Disease

Period

Up to I month

I-2 months

3-6 months

7-9 months

IO-I 2 months.

$\mathrm{I}-\mathrm{I} \frac{1}{2}$ years

$\mathrm{I} \frac{1}{2}-2$ years

More than 2 years

Total
Number of patients

$\begin{array}{r}3 \\ \text { I3 } \\ 8 \\ 4 \\ 3 \\ 3 \\ 3 \\ 7 \\ \hline 44\end{array}$




\section{TABLE VII}

\section{Type of Micturition Troubles}

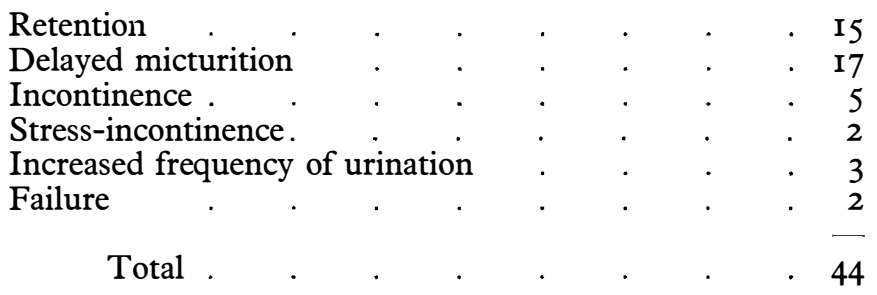

In Table VIII the time of duration of bladder disturbances is compared with the duration of the neurological disease. In the majority of cases the bladder disturbances existed for a shorter period than the nervous diseases themselves, but sometimes the bladder disturbance occurred before the first neurological manifestations.

The results of the cystometric examinations are given in Table IX. The hypotonic states of the bladder prevail in comparison with those of hypertonic type.

Analysis of the data-subdivided into age, sex, diagnosis, neurological and urological findings-show the following results with regard to the upper urinary tract:

None of the 44 patients complained about subjective troubles or disturbances of the upper urinary tract such as diffuse or colic-like pain and other complaints.

Urine analysis (Table $\mathrm{X}$ ) showed infections in two-thirds of the cases. A differentiation between isolated bladder infection and concomitant affection of the upper urinary tract was not always possible. Routine functional renal examinations showed no unequivocal pathological findings.

Intravenous urograms and cysto-uretrograms are the most important examination methods of the upper urinary tract in the case of neurogenic bladder disturbances. Conray, Byk-Gulden, Konstanz was used as contrast medium.

As may be seen from Table XI, I3 urograms showed pathological changes, and $3 \mathrm{I}$ results were normal, i.e. one quarter of our patients showed pathological findings of the upper urinary tract. These may be classified as follows:

(I) congenital anomalies of the upper urinary tract;

(2) dilatation of ureter and renal pelvis, i.e. inflammatory changes;

(3) destructions, i.e. pyelonephritis.

The results of the urograms show that every neurogenic disturbance of micturition may have an effect on the upper urinary tract. It is remarkable that in spite of considerable changes within the upper urinary tract many patients have no or hardly any subjective complaints, for instance in cases of paraplegia; the higher the localisation the less the complaints. As to differential diagnosis, therapy and prognosis this fact has to be taken into consideration.

Pathological processes in the upper urinary tract which have been overlooked may considerably influence the course of the neurological disease by decreasing the resistance of the organism-let alone the irreversible damages caused by chronic pyelonephritis. 


\section{TABLE VIII}

Duration of Bladder Disturbances in Comparison with that of Neurological Disturbances

\begin{tabular}{|c|c|c|}
\hline \multirow{2}{*}{ Case no. } & \multicolumn{2}{|c|}{$\begin{array}{l}\text { Duration of manifestations in weeks } \\
\qquad(00=>99)\end{array}$} \\
\hline & Nervous system & Urinary bladder \\
\hline I & 04 & 3 \\
\hline 2 & I6 & 8 \\
\hline 3 & 52 & 24 \\
\hline 4 & 36 & 36 \\
\hline 7 & I6 & 2 \\
\hline 8 & 52 & ০০ \\
\hline 9 & I6 & 2 \\
\hline I I & ০० & ০০ \\
\hline I3 & 36 & 36 \\
\hline 17 & I2 & OI \\
\hline 18 & ০০ & ০০ \\
\hline I9 & 06 & OI \\
\hline 26 & 24 & ০০ \\
\hline 37 & 02 & OI \\
\hline $3^{8}$ & 08 & 99 \\
\hline 39 & I2 & IO \\
\hline $4 \mathrm{I}$ & ০০ & ০০ \\
\hline 45 & 52 & 28 \\
\hline 46 & 36 & 08 \\
\hline 47 & 07 & 52 \\
\hline 48 & 72 & 72 \\
\hline 50 & 03 & 03 \\
\hline $5 \mathrm{I}$ & 99 & 99 \\
\hline 52 & 72 & 72 \\
\hline 55 & 99 & 99 \\
\hline 56 & 08 & 08 \\
\hline 59 & 08 & 08 \\
\hline 60 & 04 & 03 \\
\hline 6I & ०० & 52 \\
\hline 62 & 99 & - \\
\hline 64 & 04 & 04 \\
\hline 72 & 12 & 52 \\
\hline $8 \mathrm{I}$ & 32 & 20 \\
\hline 82 & ०० & 06 \\
\hline 84 & ০০ & ০o \\
\hline 85 & 08 & 08 \\
\hline 86 & 03 & 02 \\
\hline 87 & 04 & 04 \\
\hline 89 & 08 & 04 \\
\hline 90 & ০० & o० \\
\hline 91 & I6 & I6 \\
\hline 94 & 04 & 04 \\
\hline IOI & 72 & 72 \\
\hline 102 & ०० & ०० \\
\hline
\end{tabular}


Normotonic curve

Atonic curve .

Hypertonic curve

Hypotonic curve

Spastic curve

Hypotonic, not unequivocal finding

Hypertonic, not unequivocal finding .

Passive pressure increase .

None

Total

$$
\begin{array}{r}
r \\
\text { I } \\
8 \\
\text { I } 4 \\
4 \\
4 \\
7 \\
4 \\
4 \\
\text { I } \\
\text { I } \\
\hline 4
\end{array}
$$

\section{TABLE X}

Urine Analysis

No infection .

Slight infection

Severe infection

Total

Number of patients

Findings

\section{TABLE XI}

Urogram

None

Renal changes on both sides

Renal changes on one side

Ureter changes on both sides

Ureter changes on one side

Renal and ureter changes on both sides

Renal and ureter changes on one side

Total

$\begin{array}{r}3 I \\ 2 \\ 5 \\ I \\ 3 \\ I \\ I \\ \hline 44\end{array}$

Among 44 patients was only one case of reflux (Table XI). Analysis of reflux signs has to be made very critically. As has been pointed out by Guttmann (I968) at the last meeting in Homburg, reflux may be of absolutely transitory nature. The same applies to dilatations in the region of the ureter and renal pelvis which are also dependent upon the patient's state of hydration.

In this connection two different types can be distinguished in the region of the upper urinary tract in case of neurogenic micturition disturbances:

(I) Hydronephrosis with maintenance of function of the orifices;

(2) Hydronephrosis resulting from a vesico-ureteral reflux. As to prognosis the urinary infection plays a special part, as the infected urine is pressed into the kidney during micturition. 
If the anti-reflux mechanism is maintained in case of an atonic bladder with a capacity of $3000 \mathrm{ml}$., the upper urinary tracts may be without any pathological changes.

In summarising, one can say that in all cases of neurogenic disturbances of micturition the radiological examination of the upper urinary tract belongs to the routine examinations. The deferrent urinary tracts form a unit so that bladder diseases may affect the upper urinary tracts. This finding which has always been stressed by Alken (I968) also applies to the neurogenic disturbances of micturition.

\title{
REFERENCES
}

AdLer, A. (1920). Dtsch. Ztschr. Nervenheilkunde, 65, 72.

Alken, C. E. (1968). Leitfaden der Urologie, Thieme-Verlag, Stuttgart.

Allert, M. L., BRessel, M. \& SöKeland, J. (1968). F. Urol. belge (not yet printed).

Bors, E. \& Turner, R. D. (1967). In The Neurogenic Bladder, ed. Boyarsky, S. Baltimore:

The Williams and Wilkins Company.

Guttmann, L. \& Frankel, H. (1966). Int. F. Paraplegia, 4, 63.

Guttmann, L. (1968). Conference on Neurogenic Bladder, Homburg, in press.

Litvak, A. S., ReA, M. \& BAKER, J. (I968). F. Urol. 99, 462.

MeYER, E. (I928). Handbuch der Urologie. Edition by A. V. Lichtenberg, Berlin. F.

Voelcker, Halle, A. Wildbolz, Bern. Third volume. Berlin: Verlag J. Springer.

Talbot, A. S., Mahoney, E. M., Jarret, J. E. \& Cobb, E. (1967). Paraplegia, 5, 94.

WALsh, J. J. (1968). Int. F. Paraplegia, 2, 74.

\section{STONE FORMATION IN PARAPLEGIA}

\author{
By P. H. SMITH, M.B., F.R.C.S., J. B. Cook, M.D., M.R.C.P., and \\ W. G. ROBERTSON, B.Sc. \\ Spinal Injuries Unit, Pinderfields General Hospital, Wakefield, and M.R.C. Mineral \\ Metabolism Research Unit, The General Infirmary at Leeds, England
}

\section{INTRODUCTION}

Previous studies have established that immobilisation is associated with hypercalciuria and with a slight increase in the urine volume and the urine $\mathrm{pH}$, that aggregations of crystals detectable radiologically may be seen within seven to ten days of immobilisation, and that the majority of stones formed after immobilisation are evident within 18 months and are mainly phosphatic in nature (Leadbetter and Engster, 1945; Dietrick, Wheldon and Shorr, I948; Wheldon Dietrick and Shorr, I949; Comarr, 1955; Elliot and Todd, 1961).

The aetiological factors have been reviewed by many authors and include immobility, urinary stasis, hypercalciuria, a high urinary $\mathrm{pH}$ and urinary infection (Pyrah and Fowweather, 1938; Pulvertaft, 1939; Flocks, 1945; Leadbetter and Engster, 1945; Taylor, Alcock and Hildes, 1956; Plum, 1958; Elliot and Todd, I96I).

The adoption of a regime which involves regular turning, early mobilisation, a high fluid intake, the administration of acidifying agents and urinary antiseptics and the prevention and prompt treatment of urinary infections has resulted in a fall in the incidence of renal stone formation in patients with spinal cord injury from 20 to 30 per cent. at the end of the second world war (Riches, I943a; Prather, 